European Unions. Labor's quest for a transnacional democracy

\section{Roland Erne}

Cornell University Press, IthacaLondres, 2008

El estudio del profesor de relaciones laborales internacionales en el University College de Dublín, Roland Erne, combina dos campos de análisis tradicionalmente abordados de forma separada: la democratización de la Unión Europea (UE) y la europeización de los sindicatos. Partiendo del tantas veces constatado déficit democrático de la UE, el autor investiga el grado de europeización del movimiento sindical y su posible contribución a la democratización de la UE. Su fondo normativo proviene del filósofo alemán Jürgen Habermas, que apuesta por una «democracia transnacional». Una condición indispensable para que esa democracia independiente de identidades e instituciones nacionales pueda ser realidad es la formación de un espacio público de participación y debate europeo. Es ahí donde
Erne sitúa el papel de los sindicatos como organizaciones intermediarias entre los ciudadanos y las instituciones de la UE.

El marco conceptual de Erne se basa en cuatro tipos de estrategias sindicales frente a la UE. Una estrategia de «eurodemocratización» implica la politización de procesos de toma de decisiones en la UE y el desarrollo de una acción sindical transnacional para responder a las decisiones políticas en este ámbito. Una «estrategia euro-tecnócrata», en cambio, busca la participación de los sindicatos europeos (la Confederación Europea de Sindicatos y sus federaciones sectoriales) en el modo de gobierno dominante de la UE actual, decisiones tecnócratas lejos de un debate público democrático. Así, pueden participar en el diálogo social europeo, en el Consejo Económico y Social y en el diálogo macroeconómico como un actor más de una élite europea fuera de control democrático. Pero aún quedan dos opciones más para los sindicatos, ambas nada improbables. La estrategia de «renacionalización democrática» rechaza la integración europea como un proyecto neoliberal 
del capital y persigue el refortalecimiento del Estado del bienestar nacional, considerado mucho más avanzado y favorable para los intereses de los trabajadores. Finalmente, la «renacionalización tecnócrata» opta por pactos sociales nacionales, muchas veces incluyendo concesiones en salarios y flexibilidad, para beneficiarse de la mejor competitividad de las empresas domésticas.

El autor investiga las estrategias transnacionales de los sindicatos en dos campos: la coordinación de la negociación colectiva y la acción sindical en los comités de empresa europeos (CEU) en los procesos de fusión de grupos multinacionales. Para el primero eligió dos sectores: el metalúrgico y la construcción; para el segundo, dos procesos de fusión: el del grupo ABB Alstom Power y el de Alchan-Pechiney-Algroup.

La Federación Europea del Metal (FEM) y la Federación Europea de Construcción y Trabajadores de la Madera (FECTM) adoptaron estrategias diferentes en sus intentos de coordinar sus políticas salariales europeas. La primera optó por una fórmula homogénea de tasa de inflación más aumento de productividad para todos los países, con el fin de evitar la competencia de costes salariales, una estrategia con efectos reales muy limitados, ya que no existen mecanismos para imponer esta fórmula en los muy distintos contextos y federaciones nacionales. La segunda, confrontada con un mercado de trabajo europeizado con los trabajadores de los países de bajo coste traba- jando en las obras de los países de altos niveles salariales, defendió la autonomía nacional de política salarial contra esta presión competitiva y, al mismo tiempo, buscó alianzas entre los sindicatos de los diferentes países para controlar las condiciones de subcontratación transnacional de mano de obra. Los sindicatos de este sector lideraron las movilizaciones transnacionales contra la Directiva Bolkestein sobre la liberalización de los servicios en la UE. Esta estrategia mixta entre autonomía nacional/local y cooperaciones concretas transnacionales abre más perspectivas para una europeización eficaz que las fórmulas homogéneas carentes de mecanismos de implementación.

El capítulo del caso de la fusión entre las divisiones de energía de los grupos ABB y Alstom es uno de los más interesantes, ya que la exitosa movilización y politización del caso por parte de los sindicatos y de los comités de empresa europeos enseña las potencialidades y dimensiones de una posible europeización democrática sindical. Con movilizaciones a escala europea, con presiones sobre el Parlamento Europeo, y también a escala local, en las distintas plantas y ayuntamientos, la cooperación de sindicatos de varios países, entre ellos organizaciones tan diferentes como la francesa CGT y la polaca Solidarnosc, logró salvar la empresa de la bancarrota y reducir significativamente los cierres de plantas previstas en un plan de reestructuración. La implicación de las plantillas y los gobiernos locales, la organización de diversos encuentros 
transnacionales con el apoyo de consultorías sindicales y la firme voluntad de una serie de personas, independientemente de sus siglas e ideologías, son algunos de los elementos clave del éxito.

Que este tipo de estrategias y movilizaciones transnacionales constituyen casos muy excepcionales hasta el momento nos lo enseña el segundo caso, la fusión entre las divisiones de aluminio de Alcan (Canadá), Pechiney (Francia) y Algroup (Suiza), donde los mismos actores (FEM $y$ sindicatos de metal alemanes $y$ franceses) fracasaron en sus intentos de intervenir en las condiciones de la fusión. Sin la presión y el apoyo de sus bases, los sindicatos no podían frenar el proceso en la Comisión Europea, que aprobó la fusión sin escuchar sus objeciones.

Las conclusiones de este riguroso estudio reflejan las esperanzas del autor acerca de los sindicatos europeos en una Europa democrática. «Eurodemocratización es difícil, pero no imposible» (195). Los pocos ejemplos de estrategias sindicales transnacionales capaces de movilizar una amplia respuesta colectiva y una influencia notable en procesos europeos de decisiones políticas y empresariales sirven para demostrar las posibilidades y ventajas de la estrategia eurodemocrática frente a las nacionalistas y tecnócratas aún dominantes. Incluso suponiendo progresos en la eurodemocratización de los sindicatos —algo de por sí muy optimista-, quedan todavía muchas dudas acerca de la democratización de la UE, mientras sus gobiernos nacionales no deleguen parte de su soberanía a un gobierno y un parlamento europeos verdaderamente democráticos. Se trata, en fin, de una lectura importante e interesante.

Holm-Detlev Köhler

\section{Local Players in Global Games.} The strategic constitution of a multinational corporation.

P. H. Kristensen and J. Zeitlin
Oxford University Press, Oxford
and New York, 2005.

Este libro presenta un análisis cualitativo y evolutivo de la relación entre tres filiales y la oficina central de una empresa multinacional (EMN) de capital británico (Alfa Laval) especializada en la ingeniería de la transformación y producción de productos alimenticios y lácteos. Las tres filiales fueron adquiridas por la EMN y se sitúan en entornos de economías locales (con más o menos carácter de distrito industrial de pymes) de Dinamarca (Horsens), Reino Unido (Howard) y Estados Unidos (Lake Mills). La oficina central se sitúa en la city financiera de Londres. Los autores analizan cómo cada una de las filiales (gestores y empleados) muestra un comportamiento y una estrategia diferenciada en el seno del grupo, según los recursos que consiguen movilizar en su entorno local (formación continua, cambio de organización del trabajo, colaboración entre comité de empresa y gestores locales, etc.). Destaca la mayor capacidad 